\title{
Composição química e atividade in vitro de três óleos essenciais sobre Colletotrichum gloeosporioides do maracujazeiro
}

AQUINO, C.F." $;$; SALES, N.L.P.2; SOARES, E.P.S. ${ }^{3 ;}$ MARTINS, E.R.2; COSTA, C.A. ${ }^{2}$

(1) Universidade Federal de Viçosa, Departamento de Fitotecnia, Avenida Peter Henry Rolfs, s/n, Campus Universitário, CEP: 36570-000, Viçosa-Brasil, *cesarfernandesaquino@yahoo.com.br.

(2)Universidade Federal de Minas Gerias/Instituto de Ciências Agrárias, Avenida Universitária, 1.000, Bairro Universitário, CEP: 39404-006, Montes Claros-Brasil. (3)Universidade Estadual de Montes Claros - Unimontes, Avenida Bico da Pedra, s/n, CEP: 39440-000, Janaúba-Brasil.

RESUMO: Objetivou-se avaliar a ação de diferentes concentrações de óleos essenciais de três plantas medicinais sobre o crescimento micelial, a produção e a germinação de conídios de Colletotrichum gloeosporioides (Penz.). Utilizou-se os óleos essenciais de Lippia sidoides Cham., Cymbopogon citratus (DC) Stapf.) e Ocimum gratissimum L. em cinco concentrações $\left(0 \mu \mathrm{L} \mathrm{mL}-1,1 \mu \mathrm{L} \mathrm{mL}^{-1}, 3 \mu \mathrm{L} \mathrm{mL}^{-1}, 5 \mu \mathrm{L} \mathrm{mL}^{-1}\right.$ e $\left.7 \mu \mathrm{L} \mathrm{mL}^{-1}\right)$ com 4 repetições no delineamento inteiramente casualizado, em esquema fatorial $5 \times 3$. Os óleos foram analisados por cromatografia gasosa acoplada com espectrometria de massas. Para todas as características verificou-se efeito significativo da interação "Óleo" versus "Concentração". O óleo essencial de C. citratus proporcionou a maior inibição do crescimento micelial em todas as concentrações testadas. Os outros óleos não se diferenciaram, exceto a partir da concentração de $5 \mu \mathrm{L} \mathrm{mL}-1$, onde o óleo de $L$. sidoides foi superior ao óleo de O. gratissimum. Na produção e germinação de conídios, o óleo de $C$. citratus, foi superior aos óleos de $L$. sidoides e de $O$. gratissimum nas concentrações de $1 \mu \mathrm{L} \mathrm{mL}^{-1}$ e $3 \mu \mathrm{L} \mathrm{mL} \mathrm{m}^{-1}$, inibindo completamente a produção e germinação a partir da concentração de $3 \mu \mathrm{L} \mathrm{mL-1}$. As concentrações influenciam em todas as variáveis, ajustando-se à equação do modelo linear. Observa-se o decréscimo nessas, à medida em que se aumentam as concentrações dos óleos testados. Os óleos essenciais testados possuem efeito fungitóxico e fungistático.

Palavras-chave: Colletotrichum gloeosporioides, compostos vegetais, controle de fitopatógenos

ABSTRACT: Chemical composition and in vitro activity of three essential oils on Colletotrichum gloeosporioides from passion fruit. The objective of this study was to evaluate the action of different concentrations of essential oils of three medicinal plants on the mycelial growth, production and conidial germination of Colletotrichum gloeosporioides (Penz.). We used a completely randomized design, in a $5 \times 3$ factorial design, being five concentrations $\left(0 \mu \mathrm{LL}^{-1}, 1 \mu \mathrm{L} \mathrm{mL}^{-1}, 3 \mu \mathrm{L} \mathrm{mL}^{-1}, 5 \mu \mathrm{L} \mathrm{mL}^{-1}\right.$ e $\left.7 \mu \mathrm{LL}^{-1}\right) \times$ three oils from Lippia sidoides Cham., Cymbopogon citratus (DC) Stapf. and Ocimum gratissimum L., with four replications. The oils were analyzed by gas chromatography with mass spectrometry. There was a significant interaction of concentration versus species on all analyzed traits. The essential oil from $C$. citratus yielded the highest mycelial growth inhibition at all concentrations. The other oils were not differentiated, except at the concentration of $5 \mu \mathrm{L} \mathrm{mL}^{-1}$, in which the oil of $L$. sidoides was more efficient that the oil of $O$. gratissimum. In conidial production and germination, the oil of C. citratus was superior to the oil of $L$. sidoides and $O$. gratissimum at the concentrations of $1 \mu \mathrm{L} \mathrm{mL}-1$ and $3 \mu \mathrm{L} \mathrm{mL}^{-1}$, as it completely inhibited the production and germination of conidia at the concentrations of $3 \mu \mathrm{L} \mathrm{mL}^{-1}$ and above. The concentrations influenced all the variables, adjusting themselves to the linear model equation. We observed a decrease in the variables, as the concentrations of the oils tested are increased. The essential oils used have antifungal and fungicidal effect.

Keywords: Colletotrichum gloeosporioides, vegetable compounds, control of phytopathogens. 


\section{INTRODUÇÃO}

A cultura do maracujazeiro vem se expandindo no Brasil deixando de ser a décima quinta frutífera mais produzida no país em 2006 para ocupar a sexta posição, com área plantada de 61.630ha e aproximadamente 923 toneladas produzidas (IBGE, 2011), o que coloca o país como maior produtor dessa fruta no mundo. Essa cultura desempenha importante função social nas regiões onde é explorada. No Norte de Minas Gerais, garante emprego e renda, principalmente aos agricultores familiares.

Um dos principais entraves ao desenvolvimento dessa cultura é a ocorrência de doenças, entre elas, a antracnose (Colletotrichum gloeosporioides (Penz.)) com ocorrência em todas as regiões de cultivo do maracujazeiro-amarelo no Brasil. Em época quente e chuvosa, e na ausência de controle efetivo, causa intensa desfolha, seca de ramos e apodrecimento de frutos (Liberato, 2002), provocando a redução da produtividade das plantas, baixa qualidade dos frutos, e grandes prejuízos aos produtores.

O controle químico, feito muitas vezes de maneira não recomendada ao longo dos anos, traz graves problemas para a saúde do homem, dos animais, e para o meio ambiente, tais como a contaminação da água e do solo. Outra consequência negativa do uso de agrotóxicos é a seleção de raças do patógeno resistentes a doses crescentes (Ghini \& Kimati, 2000). Para minimizar este impacto, o uso de fungicida nas doses recomendadas, a rotação do principio ativo e do modo de ação, bem como, a busca de produtos alternativos no controle de fitopatógenos, entre eles, o uso de compostos do metabolismo secundário de plantas, tem sido constantemente pesquisado. Nesse contexto, as espécies medicinais recebem atenção especial pelas diferentes atividades que apresentam, sendo alternativas potenciais de uso como fungicidas, herbicidas, inseticidas, e nematicidas (Sodaeizadeh et al., 2010), porém, a composição química, o uso, e aação de óleos essenciais necessitam de mais pesquisas.

$\mathrm{Na}$ literatura são encontrados alguns trabalhos sobre o efeito de óleos essenciais de várias plantas no controle de fungos fitopatogênicos (Nascimento et al., 2008; Carnelossi et al. 2009; Kumar et al., 2009; Silva et al., 2009; Souza Júnior et al., 2009; Anaruma et al., 2010; Combrinck et al., 2011; Lorenzetti et al., 2011). Entretanto, existe uma grande parcela de plantas brasileiras que ainda não foram pesquisadas, e entre as estudadas, pouco se conhece sobre a composição dos seus óleos essenciais e a ação de seus compostos químicos sobre os fitopatógenos.

O objetivo desse trabalho foi investigar a composição química dos óleos essenciais de alecrim-pimenta (Lippia sidoides Cham.), capim santo (Cymbopogon citratus (DC) Stapf.), alfavaca cravo (Ocimum gratissimum L.) e avaliar a ação fungistática e fungitóxica desses óleos essenciais sobre o Colletotrichum gloeosporioides do maracujazeiro-amarelo.

\section{MATERIAL E MÉTODOS}

O trabalho foi desenvolvido no Laboratório de Fitopatologia do Instituto de Ciências Agrárias da Universidade Federal de Minas Gerais (ICA/UFMG), em Montes Claros-MG. O patógeno foi isolado a partir de lesões características da antracnose em folhas de maracujazeiro-amarelo, seguido da obtenção da cultura monospórica, conforme Alfenas e Mafia (2007). As análises cromatográficas dos óleos essenciais foram realizadas no Laboratório de Análise e Síntese de Agroquímicos da Universidade Federal de Viçosa.

Os óleos essenciais foram extraídos por arraste por vapor de água, conforme Wasicky (1989) utilizando o destilador piloto (Linax®, modelo D20). Para isso, coletaram-se amostras de $5 \mathrm{~kg}$ de folhas de cada espécie medicinal: alecrim-pimenta (Lippia sidoides Cham.), capim santo (Cymbopogon citratus (DC) Stapf.) e alfavaca cravo (Ocimum gratissimum L.) no período da manhã (07h30mim) em dia ensolarado e ausente de chuva, no mês de março de 2010, no Horto de plantas medicinais do ICA. Imediatamente após a coleta, as plantas foram levadas ao Laboratório de Plantas Medicinais do ICA e acondicionadas no destilador para extração do óleo essencial durante 3 horas. Após, o óleo foi separado do hidrolato, por partição liquido-liquido, sendo o óleo armazenado em frasco âmbar e mantido sobre refrigeração a $5^{\circ} \mathrm{C}$.

A análise consistiuda identificação e quantificação dos componentes dos óleos essenciais por cromatografia gasosa acoplada com espectrometria de massas (CG-EM) de acordo com a metodologia descrita por Adams (1995). Alíquotas $(2,0 \mathrm{mg})$ dos óleos foram pesadas em vial para derivatização e dissolvidas em $60 \mu \mathrm{L}$ de piridina e $100 \mu \mathrm{L}$ de BSTFA ( $(\mathrm{N}, \mathrm{O}-$ bis(trimetilsilil)-trifluoroacetamida) contendo $4,41 \%$ de clorotrimetilsilano. A mistura reacional foi aquecida a $70{ }^{\circ} \mathrm{C}$ por 30 min em banho-maria. $\mathrm{Da}$ solução obtida, apenas $1 \mu \mathrm{L}$ foi injetado no CG-EM, sendo o procedimento realizado em triplicata.

As análises foram realizadas no aparelho CG-EM PQ5050A da marca Shimadzu, utilizando coluna capilar de sílica fundida DB-5 ( $5 \%$ de difenil e 95\% dimetilsiloxano), com $30 \mathrm{~m}$ de comprimento, $0,25 \mathrm{~mm}$ de diâmetro interno e filme de 0,25 $\mu \mathrm{m}$

Rev. Bras. PI. Med., Campinas, v.16, n.2, supl. I, p.329-336, 2014. 
e o hélio como gás de arraste. As condições cromatográficas foram às seguintes: a temperatura do injetor foi de $290{ }^{\circ} \mathrm{C}$ iniciando com $80^{\circ} \mathrm{C}$ por 5 minutos, aumentando de $80^{\circ} \mathrm{C}$ a $290^{\circ} \mathrm{C}$ na razão de $4^{\circ} \mathrm{C} /$ minuto. A temperatura final permaneceu em $290{ }^{\circ} \mathrm{C}$ por 40 minutos. A temperatura do detector e da interface do sistema CG-EM foi de $290{ }^{\circ} \mathrm{C}$. $O$ detector de massas operou com ionização por impacto de elétrons de 70 eV e varredura de massas de 30 a $600 \mathrm{~m} / \mathrm{z}$ (Silvério et al., 2008).

A identificação dos componentes dos óleos essenciais foi realizada por comparação dos espectros de massas do banco de dados do aparelho (Wiley 330.000) com dados da literatura e também com injeção de amostras de substâncias padrão. Os padrões com $97-99 \%$ de pureza foram obtidos da Sigma-Aldrich (USA). Além disso, foi utilizado o índice de Kovats para confirmação da identificação dos compostos. A quantificação dos componentes do óleo essencial foi realizada em cromatógrafo a gás com detector por ionização em chamas (CG-FID). A atividade antifúngica dos óleos essenciais foi avaliada por meio do efeito fungistático no crescimento micelial e o efeito fungitóxico, pela ação na produção e na germinação dos conídios de C. gloeosporioides.

Para a obtenção das concentrações de óleo essencial, preparou-se solução estoque de surfactante não iônico, do produto comercial Tween $80 \circledR$ a $1 \%(v / v)$, com função dispersante para misturar água e solubilizar o óleo. No preparo da concentração de $1 \mu \mathrm{L} \mathrm{mL}^{-1}$, utilizou-se $10 \mu \mathrm{L}$ do óleo essencial em $10 \mathrm{~mL}$ da solução estoque. As demais concentrações foram obtidas, proporcionalmente para 3, 5 e $7 \mu \mathrm{LLL}^{-1}$.

Antes de conduzir os experimentos foram feitos testes para avaliar a ação fungicida do dispersante utilizado. Como não foi observada a ação do Tween $80 \AA$ sobre o fungo utilizado, prosseguiu então com os ensaios. Acrescentouse $1 \mathrm{~mL}$ de cada concentração em $19 \mathrm{~mL}$ de meio BDA (Batata-Dextrose-Ágar) fundente, resfriado até $45^{\circ} \mathrm{C}$. Em câmara de fluxo laminar, transferiu-se um disco de $5 \mathrm{~mm}$ de diâmetro da cultura monospórica para o centro de cada placa contendo as concentrações dos óleos essenciais das diferentes plantas medicinais, conforme Silva et al. (2009). As laterais das placas foram vedadas com filme de PVC para evitar possível evaporação dos compostos e ressecamento do meio de cultura. Utilizou-se o delineamento inteiramente casualizado, em esquema fatorial $5 \times 3$, sendo cinco concentrações $\left(0 \mu \mathrm{L} \mathrm{mL}^{-1}, 1 \mu \mathrm{L} \mathrm{mL}^{-1}, 3 \mu \mathrm{L} \mathrm{mL}^{-1}, 5 \mu \mathrm{L}\right.$ $\mathrm{mL}^{-1}$ e $7 \mu \mathrm{L} \mathrm{mL}^{-1}$ ) e as três espécies medicinais, com quatro repetições. Cada repetição constituiu-se de uma placa de Petri, de $9 \mathrm{~cm}$ de diâmetro. Utilizou-se como testemunha apenas meio BDA acrescido de solução estoque.

As placas foram incubadas em câmara tipo BOD com $25^{\circ} \mathrm{C}$ e 12 horas de fotoperíodo. A avaliação foi realizada por meio de medições diárias do diâmetro das colônias em dois eixos ortogonais (longitudinal e transversal), a qual iniciou-se 48 horas após a repicagem do fungo para cada placa, e finalizou-se no décimo dia. Após esse período determinou-se o Índice de Velocidade de Crescimento Micelial (IVCM) utilizando-se a equação adaptada por Oliveira (1991):

IVCM $=\sum(\mathrm{D}-\mathrm{Da}) / \mathrm{N}$,

em que: IVCM = Índice de velocidade de crescimento micelial, $\mathrm{D}=$ Diâmetro médio atual, $\mathrm{Da}$ = Diâmetro médio do dia anterior e $\mathrm{N}=$ Número de dias após a montagem do experimento (repicagem do fungo).

Posteriormente à avaliação do crescimento micelial, adicionaram-se às placas com o fungo, 10 $\mathrm{mL}$ de água destilada esterilizada, e com a alça de Drigalski, procedeu-se à raspagem das colônias para a liberação dos conídios. Após a filtragem em duas camadas de gaze esterilizada, realizou-se a contagem dos conídios produzidos em câmara de Neubauer (Silva et al., 2009).

Para avaliar o efeito dos óleos essenciais na germinação de conídios, conduziu-se outro experimento em delineamento inteiramente casualizado, em esquema fatorial $5 \times 3$, sendo cinco concentrações $\left(0 \mu \mathrm{LL}^{-1}, 1 \mu \mathrm{L} \mathrm{mL}-1,3 \mu \mathrm{mL}^{-1}, 5\right.$ $\mu \mathrm{L} \mathrm{mL}^{-1}$ e $7 \mu \mathrm{L} \mathrm{mL}^{-1}$ ) e as três espécies medicinais, com quatro repetições. Alíquotas de $30 \mu \mathrm{L}$ da suspensão de conídios $\left(2 \times 10^{7}\right.$ conídios $\left.\mathrm{mL}^{-1}\right)$ de $C$. gloeosporioides foram adicionadas sobre um bloco de meio ágar-água com $2 \mathrm{~cm}^{2}$ de área superficial, mantido sobre lâmina de vidro para microscopia esterilizada. Em seguida, adicionaram-se sobre cada bloco, alíquotas de $30 \mu \mathrm{L}$ de cada concentração do óleo essencial das diferentes espécies estudadas, cobrindo-se com uma lamínula. Após, as lâminas foram mantidas dentro de placas de vidro de 14 $\mathrm{cm}$ de diâmetro, contendo duas folhas de papel de filtro umedecidas com água destilada estéril. $O$ conjunto foi armazenado em câmaras de incubação (BOD) com temperatura de $25^{\circ} \mathrm{C}$ e 12 horas de fotoperíodo. Decorridas 18 horas de incubação, adicionaram-se duas gotas de lactofenol e azul de tripan, para, respectivamente, inibir a germinação dos conídios e facilitar a visualização dos conídios no microscópio óptico.

A germinação dos conídios foi determinada em dois campos de visão, escolhidos ao acaso, analisando-se 100 conídios por campo. Considerouse conídio germinado aquele que apresentou o comprimento do tubo germinativo maior ou igual ao diâmetro do conídio. A partir do número total de conídios computados (germinados e não

Rev. Bras. PI. Med., Campinas, v.16, n.2, supl. I, p.329-336, 2014. 
germinados), estimou-se a percentagem de conídios germinados.

Os dados de ambos os experimentos foram submetidos à análise de variância, e as médias dos dados qualitativos foram comparadas pelo teste de Tukey $(p<0,01)$ e os dados quantitativos submetidos à regressão polinomial $(p<0,01)$.

\section{RESULTADOS E DISCUSSÃO}

Foram encontrados 24 compostos no óleo essencial de $L$. sidoides. Destacam-se: timol $(30,24 \%)$, benzeno $(14,49 \%)$, trans-beta-cariofileno $(11,82 \%)$, borneol $(11,38 \%)$, metil timil éter $(8,32 \%)$ e gama-terpineno $(8,05 \%)$. Os principais constituintes do óleo de $C$. citratus foram os isômeros $E$-citral $(43,69 \%)$ e Z-citral $(34,05 \%)$ que formam o citral. No óleo essencial de O. gratissimum, o eugenol foi o constituinte químico majoritário $(92,89 \%)$ seguido pelo beta-bisaboleno $(5,92 \%)$ (Tabela 1$)$.

Veras et al. (2012) também relatam o timol como principal constituinte do óleo de $L$. sidoides (85\%), percentual muito superior ao reportado nesse trabalho, indicando que há quimiótipos nas espécies, além das condições sazonais. Pereira et al. (2008) e Combrinck et al. (2011), também observaram alto teor de citral ( $72 \%$ e $74 \%$, respectivamente) em óleo de C. citratus. Franco et al. (2007) descrevem para o óleo de O. gratissimum o predomínio do composto Eugenol, contudo, com percentual bastante inferior $(57,82 \%)$ ao observado no presente trabalho. Variações observadas nos diversos resultados de trabalhos podem ser em função da sazonalidade, fatores edafoclimáticos, e aspectos genéticos da planta (Van Vuuren, 2008).

Para o crescimento micelial, a produção

TABELA 1. Quantificação e identificação de componentes químicos em óleos essenciais de Lippia sidoides Cham., Cymbopogon citratus (DC) Stapf.) e Ocimum gratissimum L.

\begin{tabular}{|c|c|c|c|c|}
\hline $\mathrm{TR}^{1}$ & Componente químico & $\begin{array}{c}\text { Lippia sidoides } \\
(\%)\end{array}$ & $\begin{array}{c}\text { Cymbopogon citratus } \\
(\%)\end{array}$ & $\begin{array}{c}\text { Ocimum } \\
\text { gratissimum (\%) }\end{array}$ \\
\hline 9,35 & Felandreno & 0,07 & - & - \\
\hline 9,48 & Alfa-pineno & 1,92 & - & - \\
\hline 10,08 & Canfeno & 3,76 & - & - \\
\hline 12,50 & Beta-mirceno & 0,94 & 15,11 & - \\
\hline 13,46 & Alfa-terpineno & 1,16 & - & - \\
\hline 13,83 & Benzeno & 14,49 & - & - \\
\hline 15,56 & Gama-terpineno & 8,05 & - & - \\
\hline 20,93 & Borneol & 11,38 & 0,42 & - \\
\hline 24,33 & Metil timil éter & 8,32 & - & - \\
\hline 24,93 & Z-citral & - & 34,05 & - \\
\hline 26,43 & E-citral & - & 43,69 & - \\
\hline 26,75 & Acetato de bornila & 1,14 & - & - \\
\hline 27,95 & Timol & 30,24 & - & - \\
\hline 30,47 & Eugenol & - & - & $9 \overline{2,89}$ \\
\hline 30,56 & Alfa-cubebeno & 0,29 & - & - \\
\hline 31,37 & Beta-elemeno & 0,16 & - & - \\
\hline 32,46 & Trans-Cariofileno & - & - & $0 \overline{, 81}$ \\
\hline 32,50 & Trans-beta-cariofileno & 11,82 & 4,19 & - \\
\hline 33,25 & Alfa-bergamoteno & 0,23 & 0,17 & - \\
\hline 34,00 & Alfa-humuleno & 1,03 & 0,33 & - \\
\hline 35.05 & Alfa-amorfeno & 0,14 & - & - \\
\hline 35,25 & Germacreno-D & - & - & 0,38 \\
\hline 35,28 & Germacreno D/alfa-gurjuneno & 1,45 & 0,65 & - \\
\hline 35,49 & Beta-selineno & 0,22 & - & - \\
\hline 35,76 & Valenceno & 0,18 & - & - \\
\hline 35,88 & Germacreno B & 0,83 & - & - \\
\hline 36,60 & Beta-Bisaboleno & - & - & $\overline{5,92}$ \\
\hline 36,82 & Alfa-panasiseno & 0,68 & - & - \\
\hline 37,11 & Delta-cadineno & 0,51 & - & - \\
\hline 39,64 & Óxido de cariofileno & 0,99 & - & - \\
\hline
\end{tabular}

(1) Tempo de Retenção. 
e a germinação de conídios, verificou-se o efeito significativo da interação entre a concentração e a espécie. O óleo essencial de $C$. citratus proporcionou a maior inibição do crescimento micelial nas concentrações de 1 e $3 \mu \mathrm{L} \mathrm{mL}^{-1}$, diferenciando dos demais óleos testados. A partir dessas concentrações, os óleos de $C$. citratus e $L$. sidoides, foram iguais quanto a este parâmetro. $\mathrm{O}$ óleo de O. gratissimum apresentou menor efeito na inibição do crescimento micelial, em todas as concentrações (Tabela 2).

Algumas pesquisas têm demonstrado 0 potencial desses óleos essenciais como inibidor do crescimento micelial de fitopatógenos. Souza Júnior et al. (2009) e Silva et al., 2009, observaram que os óleos essenciais de $L$. sidoides, $C$. citratus e $O$. gratissimum inibiram completamente o crescimento micelial de C. gloeosporioides do maracujazeiroamarelo a partir de $1 \mu \mathrm{L} \mathrm{mL}-1$. Carnelossi et al. (2009) e Anaruma et al. (2010), verificaram que o óleo de $C$. citratus foi o mais eficiente, inibindo completamente o crescimento micelial de C. gloeosporioides isolado do mamão e do maracujazeiro a partir da alíquota de $10 \mu \mathrm{L}$. Lorenzetti et al. (2011), observaram que o óleo essencial de $C$. citratus inibiu completamente o crescimento micelial de Botrytis cinerea, isolado do morangueiro. Isso demonstra o potencial do óleo essencial de $C$. citratus na inibição do crescimento micelial de fitopatógenos.

O óleo essencial de C. citratus reduziu a produção de conídios, sendo superior aos óleos de $L$. sidoides e de $O$. gratissimum, nas concentrações de 1 e $3 \mu \mathrm{L} \mathrm{mL}-1$, entretanto, nas demais concentrações, o efeito foi semelhante para todos os óleos testados (Tabela 2). Na literatura são escassas as informações sobre o efeito de óleos essenciais sobre a produção de conídios de C. gloeosporioides. Carnelossi et al. (2009) observaram que o óleo essencial de $C$. citratus inibiu totalmente a esporulação de $C$. gloeosporioides a partir da alíquota de $10 \mu \mathrm{L}$. Lorenzetti et al. (2011), observaram que o óleo essencial de $C$. citratus (125 e 1000 ppm) inibiu completamente a esporulação de Botrytis cinerea, isolado do morangueiro.

$\mathrm{Na}$ germinação dos conídios de $C$. gloeosporioides, novamente, o óleo de $C$. citratus foi o mais eficiente, reduzindo-a, na concentração de 1 e $3 \mu \mathrm{L} \mathrm{mL}^{-1}$ e inibindo completamente a germinação a partir da concentração de $3 \mu \mathrm{L} \mathrm{mL}^{-1}$. Os outros óleos inibiram a germinação a partir da concentração de $5 \mu \mathrm{L} \mathrm{mL}^{-1}$ (Tabela 2). Souza Junior et al. (2009) e Silva et al. (2009) também observaram que os óleos de $C$. citratus, $L$. sidoides e $O$. gratissimum inibiram totalmente a germinação de conídios.

As concentrações influenciaram no crescimento micelial, na produção de conídios, e na germinação de C. gloeosporioides, ajustandose às equações de modelo linear. Observa-se decréscimo no índice de velocidade de crescimento micelial (IVCM), à medida que aumentaram as

TABELA 2. Índice de velocidade de crescimento micelial (IVCM), número de conídios/cm²(1) e percentagem de conídios germinados de Colletotrichum gloeosporioides, nas cinco concentrações dos óleos essenciais de Lippia sidoides Cham., Cymbopogon citratus (DC) Stapf.) e Ocimum gratissimum L. Montes Claros-MG.

\begin{tabular}{|c|c|c|c|c|c|}
\hline \multirow{3}{*}{ Óleos } & \multicolumn{5}{|c|}{ Concentração $\left(\mu \mathrm{L} \mathrm{mL}^{-1}\right)$} \\
\hline & \multicolumn{5}{|c|}{ Índice de velocidade de crescimento micelial (IVCM) } \\
\hline & 0 & 1 & 3 & 5 & 7 \\
\hline Lippia sidoides & 1,65 & $1,57 \mathrm{~A}$ & $1,17 \mathrm{~A}$ & $0,25 \mathrm{~B}$ & $0,20 \mathrm{~B}$ \\
\hline Cymbopogon citratus & 1,68 & $0,83 \mathrm{~B}$ & $0,36 \mathrm{~B}$ & $0,00 \mathrm{~B}$ & $0,00 \mathrm{~B}$ \\
\hline Ocimum gratissimum & 1,76 & $1,67 \mathrm{~A}$ & $1,41 \mathrm{~A}$ & $1,06 \mathrm{~A}$ & $1,04 \mathrm{~A}$ \\
\hline \multirow[t]{2}{*}{ CV\% } & \multicolumn{5}{|c|}{17,8} \\
\hline & \multicolumn{5}{|c|}{ Conídios/cm²(1) } \\
\hline Lippia sidoides & 0,05 & $0,03 \mathrm{~A}$ & $0,02 \mathrm{~A}$ & $0,01 \mathrm{~A}$ & $0,01 \mathrm{~A}$ \\
\hline Cymbopogon citratus & 0,04 & $0,01 \mathrm{~B}$ & $0,00 \mathrm{~B}$ & $0,00 \mathrm{~A}$ & $0,00 \mathrm{~A}$ \\
\hline Ocimum gratissimum & 0,05 & $0,02 \mathrm{~A}$ & $0,02 \mathrm{~A}$ & $0,01 \mathrm{~A}$ & $0,00 \mathrm{~A}$ \\
\hline \multirow[t]{2}{*}{ CV\% } & \multicolumn{5}{|c|}{30,9} \\
\hline & \multicolumn{5}{|c|}{ \% Conídios germinados } \\
\hline Lippia sidoides & 95,7 & $61,2 \mathrm{~A}$ & $39,2 \mathrm{~A}$ & $0,00 \mathrm{~A}$ & $0,00 \mathrm{~A}$ \\
\hline Cymbopogon citratus & 92,0 & $1,00 \mathrm{C}$ & $0,00 \mathrm{~B}$ & $0,00 \mathrm{~A}$ & $0,00 \mathrm{~A}$ \\
\hline Ocimum gratissimum & 92,0 & $37,0 \mathrm{~B}$ & $39,7 \mathrm{~A}$ & $0,00 \mathrm{~A}$ & $0,00 \mathrm{~A}$ \\
\hline CV\% & \multicolumn{5}{|c|}{18,99} \\
\hline
\end{tabular}

(1) Numero de conídios $\times 10^{4}$

Médias seguidas pelas mesmas letras em cada coluna, não diferem entre si pelo teste de Tukey $(p<0,01)$.

Rev. Bras. PI. Med., Campinas, v.16, n.2, supl. I, p.329-336, 2014. 


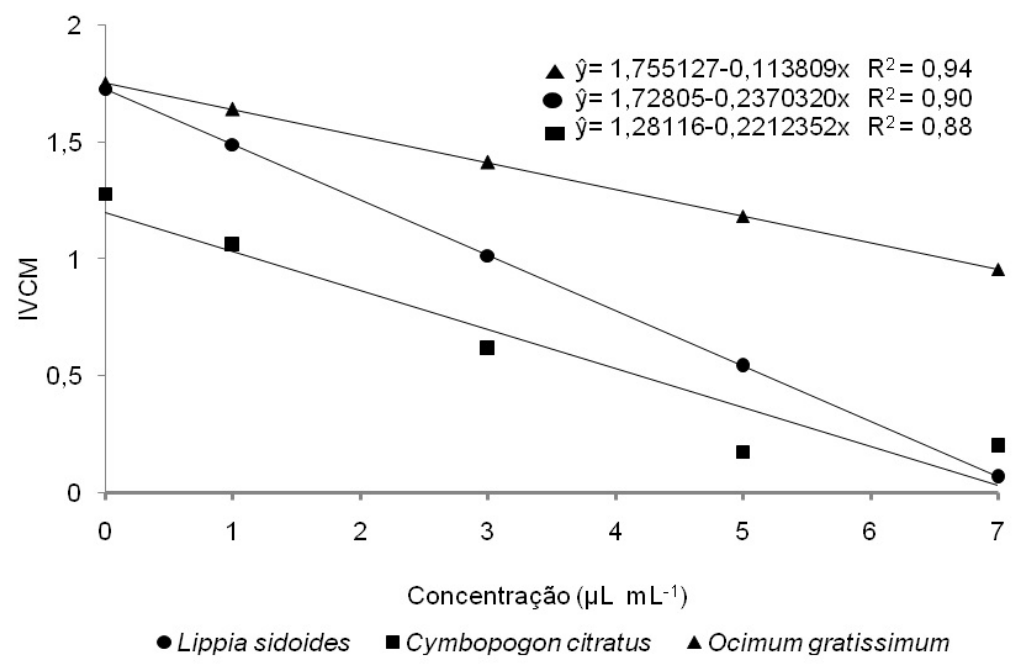

FIGURA 1. Índice de Velocidade de Crescimento Micelial (IVCM) de Colletotrichum gloeosporioides em função das concentrações dos óleos essenciais de Lippia sidoides Cham., Cymbopogon citratus (DC) Stapf.) e Ocimum gratissimum L.

concentrações dos óleos testados (Figura 1). Independente da concentração usada, o óleo de C. citratus foi o que mais reduziu o IVCM do patógeno e, já na concentração de $5 \mu \mathrm{L} \mathrm{mL-1}$, paralisou o crescimento do patógeno. Para o óleo de $O$. gratissimum, a diferença na redução do IVCM de uma concentração para outra foi muito pequena, e, mesmo na maior concentração $\left(7 \mu \mathrm{L} \mathrm{mL}^{-1}\right)$, o seu efeito foi inferior à concentração de $1 \mu \mathrm{L} \mathrm{mL}^{-1}$ do óleo de C. citratus. O óleo de $L$. sidoides reduziu o IVCM a partir da concentração de $3 \mu \mathrm{LLL}^{-1} \mathrm{e}$, na concentração de $7 \mu \mathrm{L} \mathrm{mL-1}$, paralisou o crescimento do fungo (Figura 1).

Para todos os óleos avaliados, a medida em que se aumentaram as concentrações, houve decréscimo na produção de conídios (Figura 2). A partir da concentração de $3 \mu \mathrm{L} \mathrm{mL-1}$, o óleo de $C$. citratus inibiu completamente a produção.

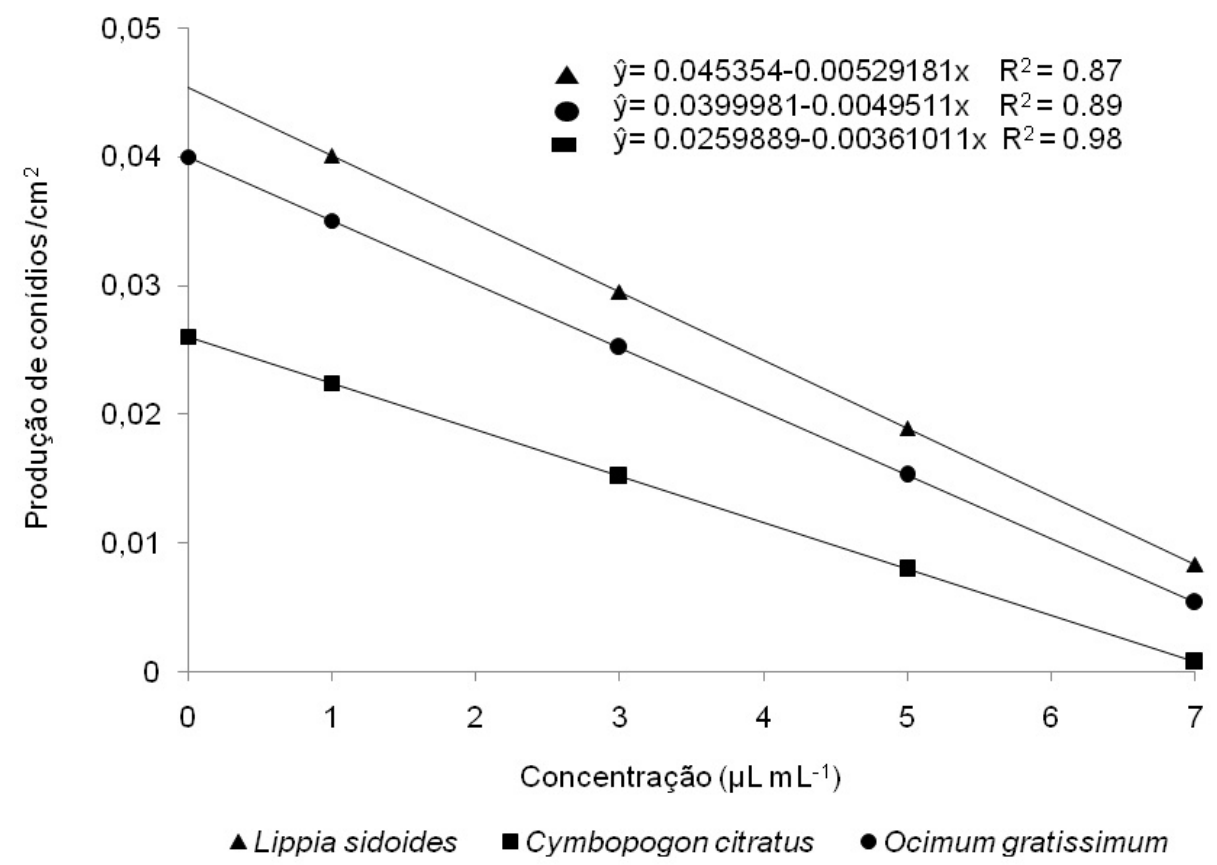

FIGURA 2. Conídios $/ \mathrm{cm}^{2}\left(\times 10^{4}\right)$, produzidos pelo Colletotrichum gloeosporioides em meio BDA nas cinco concentrações dos óleos essenciais de Lippia sidoides Cham., Cymbopogon citratus (DC) Stapf.) e Ocimum gratissimum L. 


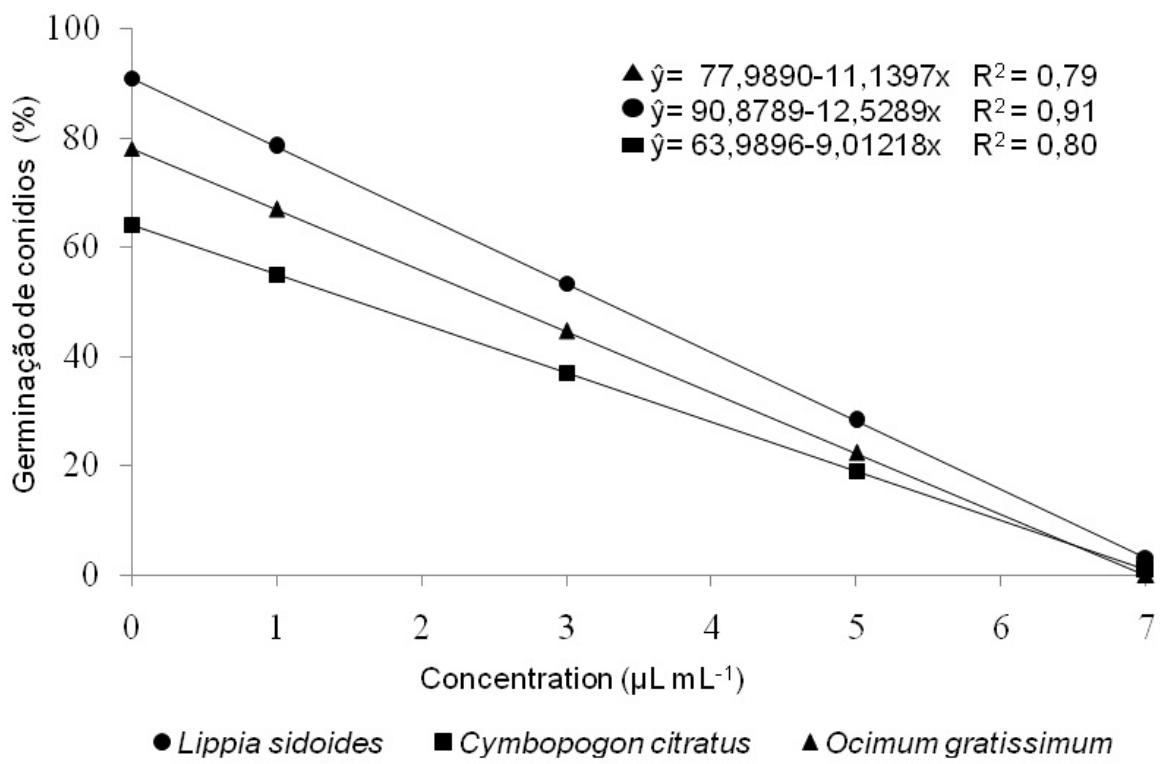

FIGURA 3. Percentagem de conídios germinados de Colletotrichum gloeosporioides, nas cinco concentrações de óleos essenciais de Lippia sidoides Cham., Cymbopogon citratus (DC) Stapf.) e Ocimum gratissimum L.

De maneira semelhante ao observado para a produção de conídios, houve decréscimo na germinação dos conídios, para todos os óleos avaliados, quando se aumentaram as concentrações (Figura 3). A partir da concentração de $3 \mu \mathrm{L} \mathrm{mL}^{-1}$ do óleo de C. citratus, e de $5 \mu \mathrm{L} \mathrm{mL-1}$ dos outros óleos, observou-se a inibição completa da germinação dos conídios.

A inibição da germinação conidial é fundamental no controle das doenças, pois esse tipo de propágulo geralmente é o ponto inicial da infecção propriamente dita. Para o uso efetivo dos óleos essenciais e seu sucesso, é preciso que eles não apenas inibam o crescimento micelial do patógeno, mas também inibam a germinação de seus conídios.

O potencial fungitóxico desses óleos pode estar relacionado aos componentes químicos com ação antimicrobiana. Botelho et al. (2007) descreve que o timol apresenta ação bactericida e antifúngica. Garcia et al. (2008), afirmam que o citral apresenta um forte efeito fungistático e fungicida, e segundo Souza et al. (2005), o eugenol apresenta atividade antimicrobiana. Pesquisas avaliando o efeito dos componentes químicos majoritários desses óleos essenciais mostraram que a ação fungistática e fungicida relatada nesse trabalho podem estar relacionadas com esses componentes, pois, Combrinck et al. (2011), ao avaliarem 18 óleos essenciais e seus componentes majoritários no controle in vitro de 6 fitopatogênicos, entre eles, o Colletotrichum gloeosporioides isolado de abacate e manga, relatam a inibição do crescimento micelial com uso de timol, citral e eugenol. Em todos os casos, a inibição de organismos fitopatogênicos pelo composto puro foi semelhante ou superior a óleos que possuem em sua composição tais compostos, Montes-Belmont \& Carvajal (1998) também observaram inibição do crescimento micelial de Aspergillus flavus. Garcia et al. (2008) avaliando o citral no crescimento micelial de C. musae, $C$. gloesporioides e de Fusarium subglutinauns f.sp. ananás, afirmam que esse componente inibiu completamente o crescimento micelial desses fungos. Kumar et al. (2009), ao testar o eugenol no controle de 12 fitopatógenos, entre eles o $C$. gloeosporioides, afirmam que esse composto exibiu potente espectro antifúngico, inibindo todas as espécies de fungos avaliadas, sendo mais eficaz que fungicidas sintéticos testados. Faria et al. (2006), também confirmam o efeito do eugenol na inibição do crescimento de Alternaria sp. e Penicillium chrysogenum.

Os resultados apresentados nesse estudo mostraram que os óleos essenciais estudados apresentam ação fungicida e que podem, futuramente, ser utilizado no manejo da antracnose em maracujazeiro-amarelo, tanto no tratamento de frutos, como no controle da doença em plantas, necessitando, no entanto, de estudos in vivo.

\section{REFERÊNCIA}

ADAMS, R.P. Identification of essential oil components by gas chromatography mass spectroscopy. Illinois: Copyright, 1995. 469p.

ALFENAS, A.C.; MAFIA, R.G. Métodos em fitopatologia. Viçosa: UFV, 2007. 382 p. 
ANARUMA, N.D. et al. Control of Colletotrichum gloeosporioides (Penz.) Sacc. in yellow passion fruit using Cymbopogon citratus essential oil. Brazilian Journal of Microbiology, v.41, n.1, p.66-73, 2010.

BOTELHO M.A, et al. Antimicrobial activity of the essential oil from Lippia sidoides, carvacrol and thymol against oral pathogens. Brazilian Journal of Medical Biological Research, v.40, n.3, p.349-356, 2007.

CARNELOSSI, P.R. et al. Óleos essenciais no controle pós-colheita de Colletotrichum gloeosporioides em mamão. Revista Brasileira de Plantas Medicinais, v.11, n.4, p.399-406, 2009.

FARIA, T.J. et al. Antifungal Activity of Essential Oil Isolated from Ocimum gratissimum L. (eugenol chemotype) against Phytopathogenic Fungi. Brazilian Archives of Biology and Technology, v.49, n.6, p. 867-71, 2006.

FRANCO, A.L.P. et al. Avaliação da composição química e atividade antibacteriana dos óleos essenciais de Aloysia gratissima (Gillies \& Hook) Tronc. (Alfazema), Ocimum gratissimum L. (Alfavaca-Cravo) e Curcuma longa L. (Açafrão). Revista Eletrônica de Farmácia, v.4, n.2, p.208-20, 2007.

GARCIA, R. et al. Antimicrobial activity and potential use of monoterpenes as tropical fruits preservatives. Brazilian Journal of Microbiology, v.39, n.1, p.163-68, 2008.

GHINI, R.; KIMATI, H. Resistência de Fungos a Fungicidas. $1^{\mathrm{a}}$ ed. Jaguariúna. Embrapa Meio Ambiente, 2000.78p.

IBGE-INSTITUTO BRASILEIRO DE GEOGRAFIA E ESTATÍSTICA. Produção agrícola/produção agrícola Municipal (Anual), 2011. Disponível em: <http://www. sidra.ibge.gov.br/bda/tabela/protabl1>. Acesso em: 05 ago. 2013.

KUMAR, A. et al. Biodeterioration of some herbal raw materials by storage fungi and aflatoxin and assessment of Cymbopogon flexuosus essential oil and its components as antifungal. International Biodeterioration \& Biodegradation, v.63, n.6, p.712-16, 2009.

LIBERATO, J.R. Controle das doenças causadas por fungos, bactérias e nematóides em maracujazeiro. In: ZAMBOLIM, L.; VALE, F.X.R.; MONTEIRO, A.J.A,; COSTA, E. (Eds.). Controle de doenças de plantas frutíferas. Viçosa, 2002. p.699-763.

LORENZETTI, E.R. et al. Bioatividade de óleos essenciais no controle de Botrytis cinerea isolado de morangueiro. Revista Brasileira de Plantas Medicinais, v.13, especial, p.619-627, 2011.

MONTES-BELMONT, R.; CARVAJAL, M. Control of
Aspergillus flavus in maize with plant essential oils and their components. Journal of Food Protection, v.61, n.5, p.616-19, 1998.

NASCIMENTO, F.R. et al. Efeito do óleo essencial de pimenta longa (Piper hispidinervum C. DC) e do emulsificante Tween $® 80$ sobre o crescimento micelial de Alternaria alternata (Fungi: Hyphomycetes). Acta Amazônica, v.38, n.3, p.503-08, 2008.

OLIVEIRA, J.A. Efeito do tratamento fungicida em sementes e no controle de tombamento de plântulas de pepino (Cucumis sativus L.) e pimentão (Capsicum annuum L.). 1991. 111f. Dissertação (Mestrado - Área de Concentração em Fitopatologia) - Universidade Federal de Lavras, Lavras.

PEREIRA, A.A. et al. Caracterização química e efeito inibitório de óleos essenciais sobre o crescimento de Staphylococcus aureus e Escherichia coli. Ciência e Agrotecnologia, v.32, n.3, p.887-93, 2008.

SILVA, A.C. et al. Efeito in vitro de compostos de plantas sobre o fungo Colletotrichum gloeosporioides: Isolado do maracujazeiro. Ciência e Agrotecnologia, v.33, n.esp., p.1853-60, 2009.

SILVÉRIO, F.O. et al. Effect of storage time on the composition and content of wood extractives in eucalyptus cultivated in Brazil. Bioresource Technology, v.99, n.11, p.4878-86, 2008.

SODAEIZADEH, $\mathrm{H}$. et al. Herbicidal activity of a medicinal plant, Peganum harmala L. and decomposition dynamics of its phytotoxins in the soil. Industrial Crops and Products, v.31, n.2, p.385-94, 2010.

SOUZA, E.L. et al. Inhibitory Action of Some Essential Oils and Phytochemicals on the Growth of Various Moulds Isolated From Foods. Brazilian Archives of Biology and Technology, v.48, n.2, p.245-250, 2005.

SOUJA JÚNIOR, I.T. et al. Efeito fungitóxico de óleos essenciais sobre Colletotrichum gloeosporioides, isolado do maracujazeiro amarelo. Biotemas, v.22, n.3, p.77-83, 2009.

VAN VUUREN, S.F. Antimicrobial activity of South African medicinal plants. J. Ethnopharmacol, v.119, n.3, 462472, 2008.

VERAS, H.N.H. et al. Synergistic antibiotic activity of volatile compounds from the essential oil of Lippia sidoides and thymol. Fitoterapia, v.83, n.3, p.508-512, 2012.

WASICKY, R. Um aparelho extrator de óleo essencial em escala piloto. Revista Brasileira de Farmacognosia, v.2, p.211-215, 1989.

Rev. Bras. PI. Med., Campinas, v.16, n.2, supl. I, p.329-336, 2014. 